\title{
CORRECTION
}

\section{Correction: The invertible electrochemical properties and thermal response of a series of gel-type ionic liquids based on polyoxometalates}

Cite this: Phys. Chem. Chem. Phys., $2015,17,30188$

DOI: $10.1039 /$ c5cp90187a

www.rsc.org/pccp

Xuefei Wu, ${ }^{a}$ Yunyan Li, ${ }^{a}$ Qingyin Wu, ${ }^{\star a}$ Hong Ding ${ }^{\mathrm{b}}$ and Wenfu Yan ${ }^{\mathrm{b}}$

Correction for 'The invertible electrochemical properties and thermal response of a series of gel-type ionic liquids based on polyoxometalates' by Xuefei Wu et al., Phys. Chem. Chem. Phys., 2014, 16, 24598-24603.

The authors regret that the incorrect photographs were used in Fig. 4 and the graphical abstract. The figure should appear as:

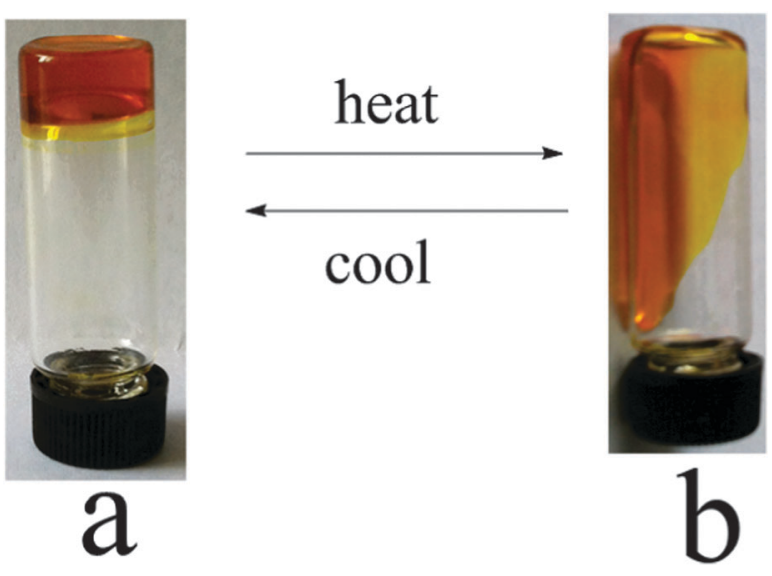

Fig. 4 Photographs of these kinds of POMs at room temperature (a) and $85^{\circ} \mathrm{C}$ (b).

The Royal Society of Chemistry apologises for these errors and any consequent inconvenience to authors and readers.

\footnotetext{
${ }^{a}$ Department of Chemistry, Zhejiang University, Hangzhou 310027, P. R. China. E-mail: qywu@zju.edu.cn; Fax: +86 $57187951895 ;$ Tel: +8657188914042

${ }^{b}$ State Key Laboratory of Inorganic Synthesis and Preparative Chemistry, Jilin University, Changchun 130012, P. R. China
} 